\title{
3D Scanning in Myofascial Dysfunction Detection
}

\author{
Wojciech KURZYDLO*1, Miroslawa M. DLUGOSZ ${ }^{2}$ \\ ${ }^{1}$ Collegium Medicum at Jagiellonian University, Krakow, Poland; \\ ${ }^{2}$ AGH University of Science and Technology, Krakow, Poland \\ http://dx.doi.org/10.15221/14.137
}

\begin{abstract}
Aim The main goal of this study was to asses the usefulness of 3D body scanning in detecting myofascial dysfunctions.

Material and Methods The study was conducted on a 14 healthy young volunteers, scanned with whole body scanner based on Prime Sense Carmine 1.09 sensor and Profactor ReconstructMe QT software.

Results In $86 \%$ of examined patients occurred the various compensations, including the global ones which concern the head and shoulders.

Conclusions Using the 3D body scanning to detecting the myofascial dysfunctions seems to be an effective and useful method.
\end{abstract}

Keywords: 3d body scanning, Prime Sense Carmine sensor, myofascial dysfunction detection, body posture compensation

\section{Introduction}

Human body posture (HBP) is a parameter used by different domains specialists: physicians, physiotherapists, fitness instructors, clothing designers, cars architects, artists and many others. In spite of the many available methods of HBP analysis used by industrial sectors, in clinical reality dominate the subjective visual assessment [1]. However the assessment of HBP seems to be really important diagnostic tool, especially because of the increasing number of evidence of the links between body posture and pain [2-12].

With the HBP is associated a term of myofascial chains, which is also used by various field specialists, including physiotherapists, osteopaths and structural integration therapists. Myofascial chains are involved in a variety of body functions, especially in maintaining proper posture. Many injuries or musculoskeletal pains arise as a result of abnormal activity of some myofascial chains or their parts [13]. Despite the high popularity of myofascial chains theory among clinicians [14-16], authors have not managed to find any publications that objectively would confirm their existence. This research is one of the first attempts to confirm the existence of this type of disorders.

Theory of myofascial chains assumes the existence of different "routes" after which somatic dysfunctions are transmitted throughout the body. Myofascial chains begin in the feet and end up on the head, what, according to theoretical assumptions, can transfer disorders even to distant parts of the body. This enables cervical problems therapy using the techniques performed on the foot, unless it is beginning of the disordered chain.

Typically there are two antagonistic to each other chains, that should balance its impact on the patient's body. If there is a tension on one of the chains, the movements performed with using of this chain should appear some asymmetries. In our study we decided to artificially stretch one of the chains on the left and right sides to measure that asymmetries.

The purpose of this paper is to create an algorithm to detect by 3D scanning the abnormalities that might indicate existence of myofascial chains and assess the usefulness of 3D body scanning in detecting myofascial dysfunctions.

\section{Material and Methods}

The study was conducted on 14 healthy volunteers aged 23-25 years. The main selection criterion of the study was lack of musculo-skeletal system disorders that affect the body posture and prevents the maintenance of a fixed standing for 60 seconds. Each volunteer was tested by method consisting in performing 3 scans of different body posture, using a prototype whole-body scanner (Figure 1) based on Prime Sense Carmine 1,09 sensor and Profactor ReconstructMe QT software. Scans were preparing in GOM Inspect V8 software.

*wojciech.kurzydlo@uj.edu.pl 
The experiment relies on taking on several postures by volunteers and keeping each one for 60 seconds scanning process. Postures measured during this study are listed below:

- relaxed

- with underlaid a $3 \mathrm{~cm}$ - height object below the right foot

- with underlaid a $3 \mathrm{~cm}$ - height object below the left foot

The first scan of the relaxed posture was considered as the reference. Remaining measurements for each patient were sequentially put on the reference scan and compared with it. Differences between two scans were visualized in the form of image mapping. Posture shift was recognized as significant if the differences between analogous points on the comparable scans were greater than $15 \mathrm{~mm}$.



Fig 1. Scheme of custom made 3D full body scanner

\section{Results}

Among the examined individuals only two patients with shortening of the lower limb did not cause any apparent compensation. The remaining patients had compensations in hip, upper limb opposite to the shortening side, head or lower limbs. The amount of compensations occurring in the above areas on the right and left side of the body are shown in Table 1.

Table 1. Compensations on the left and right side of the body.

\begin{tabular}{|l|l|l|l|l|l|}
\hline None & Lower limbs & Head & Upper limb & Hip & \\
\hline 4 & 3 & 1 & 5 & 9 & Left side \\
\hline 6 & 2 & 4 & 5 & 5 & Right side \\
\hline
\end{tabular}

In case of $43 \%$ of the patients, compensations occurred only on one side of the body, for the most part on the right side. Functional shortening of the lower limb in $36 \%$ of the patients were compensated for their head, almost in $79 \%$ cases compensations occurred at the hip, but in $64 \%$ of the patients compensations appeared at the shoulders.

An example of the global compensation functional shortening of the lower limb is shown in Figure 2. 


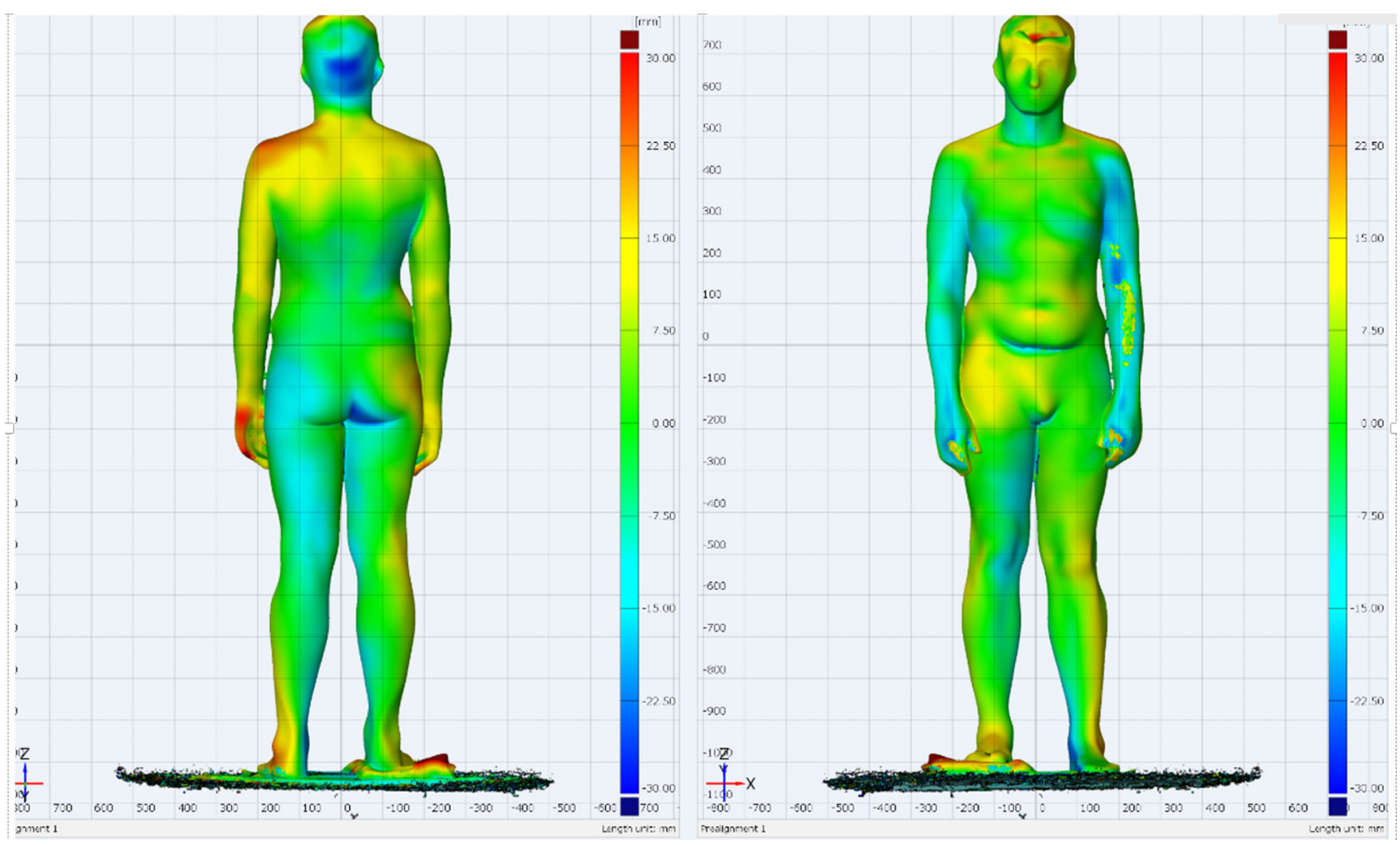

Fig. 2. An example of global compensation.

Figure 3 shows an example of a global compensation on the left. In this case on the opposite side the compensations did not occur, what is presented in Figure 4.



Figure 3. An example of global compensations on the left side. 


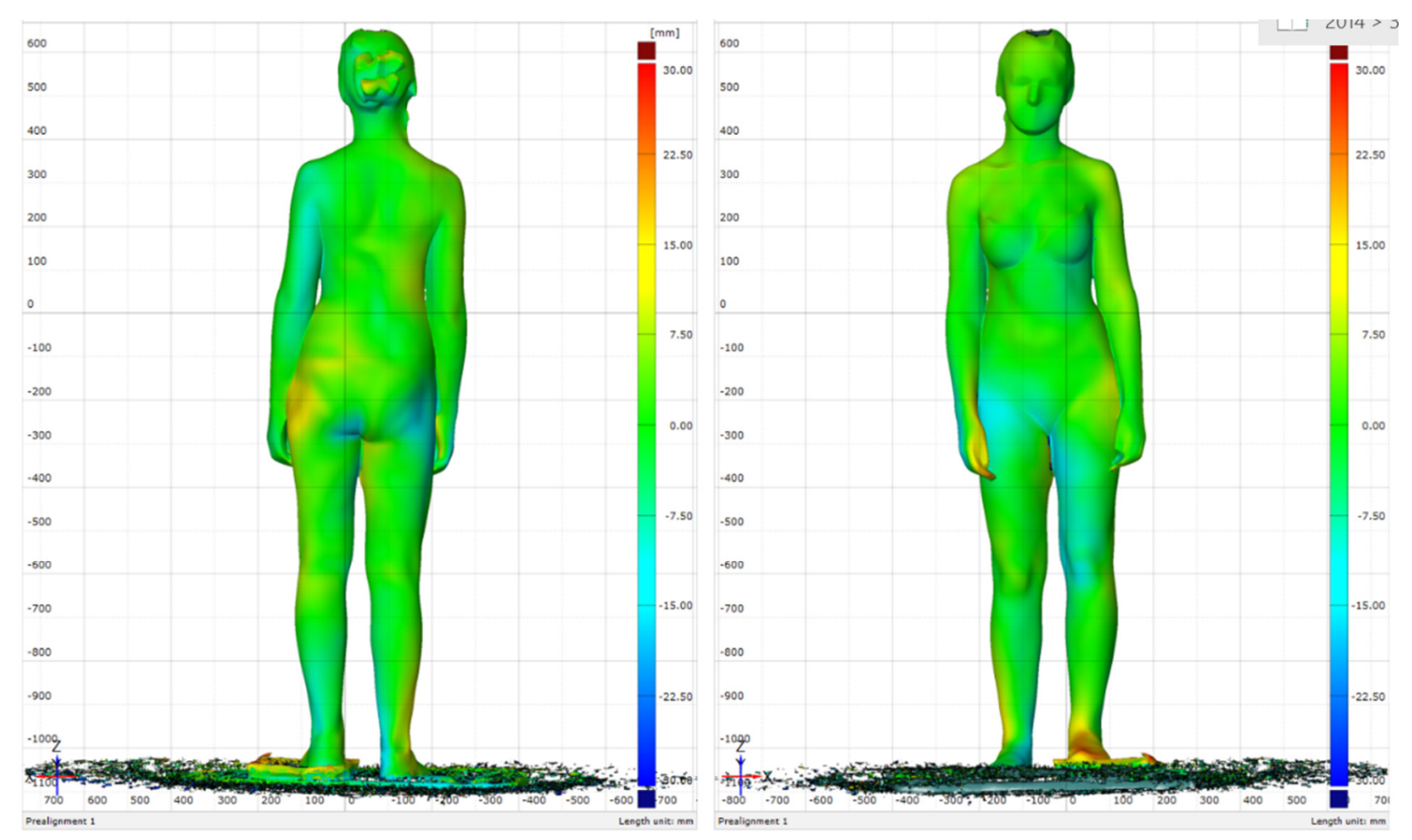

Fig. 4. An example of no compensation in functional shortening of the lower limb. Patient is the same as in the Figure 2.

\section{Conclusions}

This study reveals a large variety of compensation mechanisms, of which the most common is the pelvis shift in the transversal plane, to the direction of the foot on the pad. A large variety of the compensation patterns, including global which concern both the shoulder and head, as well as in nearly half of the patients no compensation in one of the sides may be a confirmation of the existence of myofascial chains.

This studies do not provide clear conclusions because of the small number of examined patients and the measurement error associated with movement of the patient during the scanning. However the results provide a basis for further research in this topic.

\section{Acknowledgment}

The paper is partly supported by the AGH UST grant no. 15.11.120.407.

\section{References}

1. A.G. Silva, T.D. Punt, M.I. Johnson. Reliability and validity of head posture assessment by observation and a four-category scale. Manual Therapy. Manual Therapy 2010;15(5):490-495.

2. D.E. Carvalho de, D. Soave, K. Ross, et al. Lumbar Spine and Pelvic Posture Between Standing and Sitting: A Radiologic Investigation Including Reliability and Repeatability of the Lumbar Lordosis Measure. Journal of Manipulative and Physiological Therapeutics. Journal of Manipulative and Physiological Therapeutics 2010;33(1):48-55.

3. N.M. Dunk, Y.Y. Chung, D. Sullivan Compton, et al. The reliability of quantifying upright standing postures as a baseline diagnostic clinical tool. Journal of Manipulative and Physiological Therapeutics. Journal of Manipulative and Physiological Therapeutics 2004;27(2):91-96.

4. N.M. Dunk, J. Lalonde, J.P. Callaghan. Implications for the Use of Postural Analysis as a Clinical Diagnostic Tool: Reliability of Quantifying Upright Standing Spinal Postures From Photographic Images. Journal of Manipulative and Physiological Therapeutics. Journal of Manipulative and Physiological Therapeutics 2005;28(6):386-392.

5. C. Fortin, D.E. Feldman, F. Cheriet, et al. Reliability of a quantitative clinical posture assessment tool among persons with idiopathic scoliosis. Physiotherapy. Physiotherapy 2012;98(1):64-75. 
6. Y. Kuo, E.A. Tully, M.P. Galea. Video Analysis of Sagittal Spinal Posture in Healthy Young and Older Adults. Journal of Manipulative and Physiological Therapeutics. Journal of Manipulative and Physiological Therapeutics 2009;32(3):210-215.

7. N.A. Nelson, R.E. Hughes. Quantifying relationships between selected work-related risk factors and back pain: A systematic review of objective biomechanical measures and cost-related health outcomes. International Journal of Industrial Ergonomics. International Journal of Industrial Ergonomics 2009;39(1):202-210.

8. K. O'Sullivan, P. O'Sullivan, L. O'Sullivan, et al. What do physiotherapists consider to be the best sitting spinal posture? Manual Therapy. Manual Therapy 2012;17(5):432-437.

9. J. Paušić, Ž. Pedišić, D. Dizdar. Reliability of a Photographic Method for Assessing Standing Posture of Elementary School Students. Journal of Manipulative and Physiological Therapeutics. Journal of Manipulative and Physiological Therapeutics 2010;33(6):425-431.

10. A. Reeve, A. Dilley. Effects of posture on the thickness of transversus abdominis in pain-free subjects. Manual Therapy, 2009;14(6):679-684.

11. A.G. Silva, T.D. Punt, P. Sharples, et al. Head Posture and Neck Pain of Chronic Nontraumatic Origin: A Comparison Between Patients and Pain-Free Persons. Archives of Physical Medicine and Rehabilitation. Archives of Physical Medicine and Rehabilitation 2009;90(4):669-674.

12. G.R. Tomkinson, L.G. Shaw. Quantification of the postural and technical errors in asymptomatic adults using direct 3D whole body scan measurements of standing posture. Gait \& Posture 2012.

13. P. Richter and E. Hebgen, Trigger points and muscle chains in osteopathy, Thieme, USA, 2008.

14. T. W. Myers, Anatomy Trains. Myofascial Meridians for Manual and Movement Therapists, Churchill Livingstone, Elsevier, 2001

15. R. Schleip, T. W. Findley, L. Chaitow, P. A. Huijing, Fascia. The tensional network of the human body. Churchill Livingstone, Elsevier, 2012

16. M. Romanowski, Łańcuchy mięśniowo-powięziowe. Charakterystyka taśm anatomicznych. Kwartalnik Medycyna Manualna, v. 2, p. 13-19, 2011. 